\title{
Review on Sport for Semiotic Area of Culture
}

\author{
Klimov Mikhaill Yuryevich* \\ Associate Professor, Department of Physical Education, Russia
}

ISSN: 2637-7934

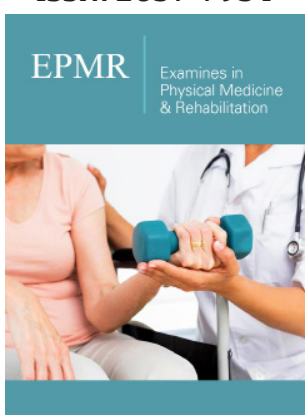

For HTML Version scan this QR code:

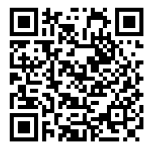

${ }^{* 1}$ Corresponding author: Klimov Mikhail Yuryevich, Associate Professor, Department of Physical Education, Russia

Submission: 泟 December 12, 2018

Published: : March 07, 2019

Volume 2 - Issue 2

How to cite this article: Klimov $M$ Y.Review on Sport for Semiotic Area of Culture. Examines Phy Med Rehab. 2(2). EPMR.000535.2019.

DOI: 10.31031/EPMR.2019.02.000535

Copyright@ Klimov Mikhail Yuryevich, This article is distributed under the terms of the Creative Commons Attribution 4.0 International License, which permits unrestricted use and redistribution provided that the original author and source are credited.

\section{Mini Review}

According to the definition of Umberto Eco, semiology is examining all facts of culture as a sign system, assuming that it is really it, being thus also phenomenon of communication [1]. The purpose of this work is to research sport as a phenomenon of sign communication and its place in semiotic area of culture. Sport is a conditional, gaming system, containing communicative sign system, having no practical, domestic significance. This implies the following definition: sport is a corporal competition by strictly defined rules with the aim to determine the winner. It is the body, which forming a meaningful gesture, represents the main and special content of sport as a semiotic system. Sportsman is running, jumping, changing the pose, striking-all these actions at the same time are the acts of communication with whose help he is telling something to others, while others draw conclusions about him for the same actions. All actions of the athlete are carried out within the rules, the basic postulate of which is the provision of equal conditions to the competitors. All rules of any sport provide mandatory determination of the winner. Every closed system has its own spatial boundaries. Principles and rules of sport, and objects, structures and people, taking part in sport activity, taking place only in this space. Of course, fans and athletes do not disappear, leaving the stadium. They move to other cultural spaces, turn into ordinary people engaged in everyday life and become members of other social systems: a family, an enterprise or an educational institution, a club of interests. Also (Either), the items and facilities (objects and structures), that are necessary and compulsory in (for) sport competition, are absolutely (completely, totally) unsuitable for other purposes.

Sport as a conditional system needs in detachment (distinction, removal) from the surrounding reality. In order to play sports rules, work closed space from outside impact is needed, inside which they could be realized, and certain (definite) time during which they are valid too. These space and time have its own particular (specified) reference systems, existing (taking place) only in the system of sport competitions. Levi-Strauss allocates (identifies) special space and time, inherent (intrinsic, immanent) in the social environment: Space and time are the two reference systems, which allow to consider social relations-in its aggregate (total) and separately (apart). These dimensions (measurements) are not mixed with dimensions (measurements), used by other sciences, in space and time. They are social space and social time; this means that they have only the properties of social phenomena that fill them [2]. There is a clear definition of the space in the rules of any sport where these rules are applying (operating, affecting): a football field, a ring, a running track (path), etc. Typical (common) road can be the sport space. It is worth to measure a certain distance and close within the start and finish line-marathon track (route) is ready. If a sportsman (athlete) leaves the conditional boundaries of such (this) space, he is disqualified and leaves (eliminated) the competition. In several sports (jumps and throwing in athletics) space is (serves) as a criterion for the result-an athlete who jumped furthest of all (or sent a projectile as far as he can) become a winner. In other kinds (running, skiing, swimming) a time (usually the smallest), which spent on overcoming the space, is (stands) as the suchcriterion. In sport time can change places with space-when time interval is the boundary of distance (an hour or daily running), and the winner is identified by the largest distance traveled. In this case, the composition of the categories filling this structure changes in the semiotic structure of the sport. So, the competition in running at a distance of $10 \mathrm{~km}$, the category of the form 
corresponds to the distance (space), the content of the competition is the running itself (movement), and the total time as a result refers to the value category.

When the competitions in the hour run (and world records are fixed) are held, the form is already time, the content remains the same-running, and the overcome space as a result becomes the value. The most important essential quality of sport, along with knowing yourself and aspiration to victory, is overcoming space and time, denying them. World records reflect a continuous (sustained) desire to overcome space and time. Negation of spacetime categories is expressed not only in a literal form-(but also) quantitative-digital indicators, when an athlete jumps on or runs faster than his predecessors. Outstanding world achievements, sharply changing the previous (former) boundaries of human capabilities, acquire an iconic, semiotic character. Such records overcome space and time already in the minds of contemporaries, in their assessment of the events. In 1968, at the Olympic Games in Mexico, the little-known US athlete Bob Beamon at the long jump competitions in the very first attempt set a world record of $8 \mathrm{~m} 90 \mathrm{~cm}$. The previous record was equal to $8 \mathrm{~m} 35 \mathrm{~cm}$ and belonged, by the way, to two sportsmen. If before the jumpers added to the record indicators a few centimeters every few years, Beamon cut off the previous achievement immediately more than half a meter. This result seemed unreachable in the fore see able future, it went beyond of this time and was named the jump into $21^{\text {st }}$ century. In the other kind of sports, where the world records are not fixing, negotiation of space and time manifests indirectly. The win (victory, triumph) in competition of any level means admission (intercourse) to history. A team or a sportsman, who became the champion, enter in the annals of the sport and acquire titles, which are added to the name now. The higher status of competition the more significant champion title becomes. The name world champion indicates the highest achievement-a man has surpassed all, people living on earth, in activity. The highest attainment is the title of Olympic champion in the world of sports. Every World Cup re-plays the title with a victory of another athlete, the former becomes the exchampion.

The Olympic champion bears this title for life and remains forever in the history of sports-he is attached to (the) eternity. Thus, the negation of space and time can be attributed to the essential sports category as the semiotic structure, which we defined as the sense or meaning. The other category of semiotic sport structure-a shape-determines the structure and organization of the competition (Games).The game is impossible without space and time parameters. Space and time define the boundaries, in which sport is functioning as the conditional, closed semiotic system. Conditionality and closedness of sport are necessary (needed) for communication-transferring information from competitors to spectators and fans. For the gaming communicative system to function, knowledge of the laws and principles of the Game (signs, code and language) and awareness of oneself as a member of the sport action is compulsory. Closedness and conditionality are inherent not only in sports as a communicative system. Any semiotic communicative system has a similar structure. The most important condition of such system's being is the existence of common sign organization, single code. A semiotic sport's space-time continuum has a different incarnation and measurement. The place, where the visual sports text unfolds, will be denoted as a game semiotic space. Such space is measuring by ordinary physical quantitieslength, height and width. One kind of game semiotic sport space is the territory of the Game. It's always a kind of geometric figure: rectangle (football field, volleyball and basketball courts), square (boxing ring), circle (wrestling mat), ellipse (hockey box), etc.(and so on). Such space is always symmetric. Let's remind, that one of the basic sports rules' postulates is the observance of equal conditions for all participants (of the competition). In sports games there are two rivals, each of whom owns half of the game space. These halves must be the same (identical). Moreover, the team or the players change their places after each conditional stretch of the match. Semiotic game space can be changeable (alterable) and shows different amount (value) amongst each competition's participants. Such space will be called internal (inner, inside). The internal space is in those sports where semiotic space serves as a criterion for the result. The athlete overcomes the vertical (jumps in height, diving in depth), horizontal (long jumps), sends a sports projectile to a certain distance (shot put, throwing a spear) or to a target (archery, bullet shooting). Two types of space are simultaneously represented here: internal and external. The external semiotic space is invariable, it acts as a form and is the playground where the competitions take place (the sector for jumping, the throwing circle, the distance to the target and the target itself). The internal semiotic space of each athlete individually determines its result.

The game semiotic space is a semiotic structure in which the common to all similar systems rules operate. Game semiotic space is clearly divided into two conditional halves. In addition to the semiotic space within which the game action itself (the stage part), there is still a spectator space (the behind-the-scenes part). Stadium unites these two parts in a common semiotic space. The behind-the-scenes part can go beyond the stadium - in the space of direct TV coverage or the Internet on- line. The athlete always feels the presence of the viewer. This connection, which does not directly affect the process of the Game, acquires in modern sport an ever-increasing expression. Semiotic sport space is a conditional speculative system. Despite the lack of physical parameters, the semiotic space of sports is as real phenomenon as any other sphere of the common cultural space, for example, literature. The main feature of the semiotic literature space (as opposed to architecture or theater) is the conventionality and imaginability. The real fact is only a small rectangle of stitched pressed paper of standard sizes. On external spatial characteristics, such book is no different from millions of others like it. And only after opening this book and reading into a combination of the same standard letter-symbols, we suddenly plunge into another space filled with oceans, continents and states, populated (inhabited) by numerous (many) peoplecharacters. This space can be the territory of some city or house and can expand to the size of the universe. A multitude of diverse spaces of individual books all together constitute a single semiotic space of literature. Such space is as real as the natural landscapes of the subcontinents. Curious semiotic metamorphosis can occur with these landscapes. A huge literary world unfolds from the pages of 
a small opened book. Our own real, extended and populated world can be collapsed to the size of a small geographic map filled with conditional icons. In the public consciousness fictional literary heroes (characters) have a real being (existence), much more authentic, real and vivid than the living images of millions obscure contemporaries.

Semiotic sport space is only a part of a single semiotic spacethe common cultural field necessary for the existence of signs and languages.(Y. M.)Lottman calls such space a semi sphere, by analogy with (V. I.)Vernadsky's biosphere: Any single language is immersed in a semiotic space, and only because of the interaction with this space it is able to function. An indissoluble working mechanism-a unit of semiosis-should not be considered a separate language, but all the semiotic space inherent in this culture. This space is defined as a semiosphere [3]. In the semiotic space of sport only its own, specific languages and texts are valid. The conditional and closed nature of the semiotic sport system does not isolate this space from interaction with other semiotic spaces. The sign sports system is included in the semiosphere along with other semiotic phenomena. Lotman explains: The semiosphere is not homogeneous. The semiosphere has different heterogeneity.) The languages that fill the semiotic space are different in nature and refer to each other in the spectrum from complete mutual translatability to equally complete mutual untranslatability» [Ibid: 252]. Closedness of the sport determines the closedness of the semiotic sport space those conventional sign boundaries in which it operates. Such closedness does not mean complete isolation of the semiotic sport space from the common cultural space-the semiosphere. The sports texts' penetration into the semiotic space of other cultural phenomena and reverse processes can be observed everywhere. With the rising sport role in modern society and the expansion of its semiotic space in the world information field, semiotic interchange is only increasing. So, according to Lyushen, the famous expression that is not legal, applied to those who are dishonest in life, originally appeared in cricket and then has become widespread [4].

\section{Sport has an impact on various aspects of modern society}

Sports texts penetrate the semiotic boundaries of other cultural areas, changing the picture of the semiotic space of these cultures. Lotman writes: The space's semiotics has an exceptionally important, if not dominant, significance in creating a picture of the culture's world. The phenomenon's nature is related to the very specifics of space. An unavoidable foundation for the mastery of life by culture is the creation of an image of the world, a spatial model of the universe. In this case, spatial modeling reconstructs the real world's spatial appearance [3]. We have already mentioned that the closed nature of sport as a semiotic system does not mean its complete isolation. The invasion of the languages of other semiotic spaces into the world of sport is a frequent and very common phenomenon. Political texts have always influenced the semiotic sport space. The most striking examples of direct invasion of such texts-Boycotting the Olympic Games in 1980 and 1984 the world's leading countries, which led to a change in the semiotic space: at these Olympiads many champions and world record-breakers on various sports did not take part. This devalued the significance of the Olympic victories somewhat. However, the Olympic title is so valuable, is now, after some time, the winners of the Olympic Games are no less important than the other. One can also recall the ideological confrontation of the Cold War: sports rivalry was seen as a model of a military clash. In 1968, the United States experienced acute racial unrest. At the Olympic Games in Mexico, two black athletes-Tommy Smith and John Carlos, who took the first and third places standing on a pedestal during the performance of the American anthem, bowed their heads and raised their hands, dressed in gloves and clenched fists at the award ceremony for 200 meters. Thus, they expressed solidarity with the oppressed tribesmen. Here (in this case) the semiotic sport space does not just intersect with the political one. This scene has a profound symbolic meaning: the whole world order is condemned, where the best athletes of the world who glorify their country are citizens of the second class in this state. Economy has even more significant impact on the modern sports. Most professional clubs in various sports-basketball, hockey, football, baseball-are organized as a joint stock company with the entire management structure inherent in such enterprise. Shares of these clubs participate in exchange transactions along with steel, oil and other companies. Players enter into contracts with these clubs as hired employees and can be objects of sale. Here, the athlete is estimated not only by playing skills, but also by the value of the contract. Usually these values are the same-the higher the skill of the athlete, the more expensive it is. The overlapping of semiotic spatial boundaries of sports and art can be observed everywhere. Long ago sport has been presented in various genres of art as images and plots. At the largest world sports events-the Olympics and the world football championships-there is certainly an extensive cultural program. Here, it is honored to be invited as a participant for prominent artists, and the opening and closing ceremonies have become grand theatrical performances. Modern sport cannot exist separately from the whole cultural space. Numerous connections unite the semiotic space of sports with almost all the semiotic spheres of modern society. The boundaries of the semiotic sports space are open to other semiotic spaces, the mutual penetration of languages and texts. Semiotic space of sports is organically included in the general semiosphere. This rule does not apply to the primary semiotic space of sports: gaming semiotic space is a closed and limited area-it is a necessary and obligatory condition for the existence and functioning of such a space.

\section{References}

1. Eco U (2004) Otsutstvuiaschaiastructura. vvedenie v semiologiu-St. Petersburg, Simposium, pp. 544.

2. Lévi Strauss C (2001) Structurnaiaanthropologia-M: Exmo-press, pp. 512.

3. Lotman YM (2000) Semiosfera-SPb: Iscusstvo-SPb, pp. 704.

4. Luschen G (1980) Vsaimosavisimostmehzdusportom I culturoy. Sport v sovremennomobshestve-M: Phiscultura I sport, pp.35-51. 